\title{
Progression of HIV disease in a haemophilic cohort followed for 11 years and the effect of treatment
}

\author{
Christine A Lee, Andrew N Phillips, Jonathan Elford, George Janossy, Paul Griffiths, Peter Kernoff
}

Abstract

Objective-To describe the progression of HIV disease in a haemophilic cohort and to show the influence of treatment.

Design-11 year longitudinal clinical and laboratory study.

Setting-A haemophilia centre.

Patients-111 patients infected with HIV during October 1979 to July 1985.

Main outcome measures-Symptoms of HIV infection, AIDS, and death.

Interventions -26 asymptomatic patients started taking zidovudine or placebo $(1000 \mathrm{mg} / \mathrm{day})$ during November 1988 to February $1990 ; 10$ patients with $\mathrm{CD} 4+$ counts of $0.2 \times 10^{\circ} / 1$ started zidovudine $500 \mathrm{mg} /$ day during January to November 1990. 35 patients used pentamidine for primary or secondary prophylaxis.

Results-At 11 years from seroconversion the estimated rate of progression to AIDS was $42 \%(95 \%$ confidence interval $27 \%$ to $57 \%$ ); to symptoms $85 \%$ ( $75 \%$ to $95 \%)$; and to death $41 \%(25 \%$ to $57 \%)$. Progression to AIDS was significantly faster in 25 (relative risk $5.0(2.4$ to 10.4$) ; p<0.00001)$ and in those with previous cytomegalovirus infection than in those not infected (relative risk 3.0 (1.4 to 6.8); $p=0.006) .16$ of $27(59 \%)$ patients with $p 24$ antigenaemia developed AIDS compared with 17 of $84(20 \%)$ patients without $\mathrm{p} 24$ antigen $(\mathbf{p}<\mathbf{0 . 0 0 1})$. The risk of progression to AIDS before 30 November 1988 in patients with $\mathrm{CD} 4+$ counts $\leqslant 0.2 \times 10^{9} / 1$ was higher than after November 1988 (relative risk $1.9(0.85$ to 4.43); $p=0 \cdot 1$ ). For 1989 and 1990 the observed cumulative numbers of AIDS cases (among 81 patients with sufficient CD4 + counts) were 22 and 25 compared with 29 and 37 predicted from the rate of fall of CD4 + counts up to the end of $1988(p=0.03)$.

Conclusion-Treatment seems to be reducing the progression of HIV disease in this haemophilic cohort.

consultant haematologis

Peter Kernoff, FRCP,

director, haemophilia centre

Royal Free Hampstead and Royal Free Hospital School of Medicine, London NW3 2QG

Andrew N Phillips, PHD, lecturer in statistics Jonathan Elford, PHD, lecturer in epidemiology George Janossy, DSC, professor of immunology Paul Griffiths, MRCPATH, professor of virology

Correspondence to: Dr Lee.

BMJ 1991;303:1093-6

\section{Introduction}

In a previous study we followed up a cohort of haemophiliac patients infected with HIV and described the natural course of HIV infection in these patients. ${ }^{1}$ This follow up ended before treatment was introduced for patients without AIDS and we found progression rates similar to those in the large San Francisco City Clinic cohort of homosexual men. ${ }^{2}$ We have now extended our follow up to consider further the effects of age, cytomegalovirus, and p24 antigenaemia and the influence of treatment which was first introduced for patients without AIDS in November 1988. We describe the progression of HIV disease in this cohort followed from time of first seroconversion in 1979 to November 1990. patients aged 25 and over than in those aged less than

Patients and methods

PATIENTS

We entered 111 patients with antibodies to HIV into the study using data from records and samples taken during 1 December 1979 to 30 November 1990. Of the patients, 101 had severe haemophilia A (factor VIII $<0.2 \mathrm{U} / \mathrm{l}$ ), seven had moderate or mild haemophilia A (factor VIII $>0.2 \mathrm{U} / \mathrm{l}$ ), one severe haemophilia $\mathrm{B}$ (factor IX $<0.2 \mathrm{U} / \mathrm{l}$ ), and two von Willebrand's disease. ' All except two patients had received unheated factor VIII concentrates; one had been treated with unheated factor IX concentrate and the other with cryoprecipitate.

For 63 patients the dates of their last negative and first positive HIV antibody test result were available. The date of HIV seroconversion was estimated as the midpoint between these two dates (median difference between the dates 11 months, range 15 days to 24 months). The earliest seroconversion was October $1979^{3}$ and the latest July 1985. Within this range patients' estimated dates of seroconversion followed an approximately uniform distribution. For 36 of the 48 patients in whom no negative test result was available the date of seroconversion was estimated as the midpoint between October 1979 (the presumed first possible date of infection) and the date of the first positive HIV test result (median difference 44 (range $1 \cdot 5-67$ ) months). For the remaining 12 patients the first positive HIV test result was after the presumed last possible date of infection (July 1985), and the date of seroconversion was estimated as the midpoint between October 1979 and July 1985 - that is, September 1982 (difference 68 months). The median age at seroconversion was 24 years (range 2 to 77 years).

\section{TREATMENT}

Zidovudine-Zidovudine was first used to treat AIDS in August 1987 when efficacy had been reported in the treatment of AIDS and AIDS related complex. ${ }^{4}$ We first treated asymptomatic patients with zidovudine $(1000 \mathrm{mg} /$ day $)$ in November 1988 as part of the Medical Research Council Concorde trial. By February 1990, 26 patients had been entered into the trial. In January 1990 we started patients with a CD4+ patients had been treated by November 1990 .

Pentamidine-Since March 1988 nine patients have received secondary prophylaxis against pneumocystis pneumonia. Patients used $300 \mathrm{mg}$ nebulised pentamidine fortnightly delivered with a modified acorn system $^{5}$ containing a baffle valve which produced optimal droplet size. ${ }^{6}$ In addition, 26 patients with a CD4+ count less than $0 \cdot 2 \times 10^{9} / 1$ have used primary prophylaxis ( $300 \mathrm{mg}$ monthly) since February 1989 , when this was first introduced according to the recommendations of Morbidity and Mortality Weekly Reports.? Thirty four of the 35 patients have self administered pentamidine at home. 
Treatment for thrombocytopenia-Nine patients developed thrombocytopenia defined by a platelet count less than $50 \times 10^{9} / 1$ and various treatments have been used including steroids, immunoglobulin (IgG), splenectomy, zidovudine, and intravenous interferon.

\section{STATISTICAL METHODS}

We used the methods of Kaplan-Meier to estimate the cumulative incidence of clinical disease. ${ }^{8} \log$ rank tests and the Cox proportional hazards model were used to test the difference in progression rates between patients positive and negative for cytomegalovirus infection and between older and younger patients. The differences between observed $(\mathrm{O})$ and expected $(\mathrm{E})$ numbers of cases of AIDS were tested by estimating the standard error of $\log (\mathrm{O} / \mathrm{E})$ to be $1 / \sqrt{\mathrm{O}} .^{9}$ The CD4+ count at the time AIDS was diagnosed was estimated by linear interpolation of the counts made immediately before and after the diagnosis. For patients where no count was available after the diagnosis of AIDS the last available count was used provided this was within the previous six months.

\section{Results}

PROGRESSION OF HIV DISEASE

Figure 1 shows the Kaplan-Meier estimate of progression to disease and death. The estimated rate of progression to symptoms, including severe bacterial infections, seborrhoeic dermatitis, oral candidiasis, herpes zoster, and thrombocytopenia at 11 years after seroconversion was $85 \%$ (95\% confidence interval $75 \%$ to $95 \%)$. The estimated rate of progression to AIDS was $42 \%(27 \%$ to $57 \%)$ in all patients and $45 \%$ (30\% to $60 \%)$ in the 61 patients for whom the date of the last negative HIV test result was known. Progress to death was estimated at $41 \%$ (25\% to $57 \%)$. Thirty one deaths occurred up to November 1990, three of which were not related to HIV (suicide, aspiration of vomit in a patient with known epilepsy, and cerebral haemorrhage).

By 30 November 1990, 33 patients had developed AIDS. The first AIDS defining illnesses were pneumo-

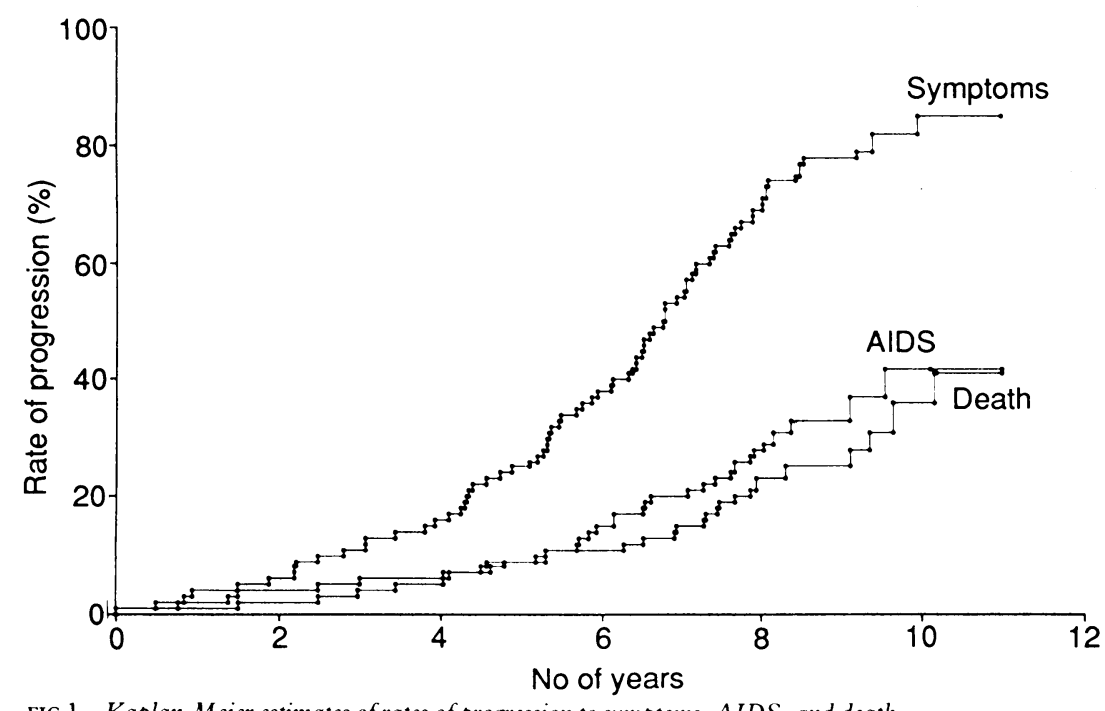

FIG 1-Kaplan-Meier estimates of rates of progression to symptoms, AIDS, and death

Risk of progression to AIDS up to and after November 1988 according to CD4+ count

\begin{tabular}{|c|c|c|c|c|c|c|c|}
\hline \multirow[b]{2}{*}{$\begin{array}{l}\text { CD4+ count } \\
\left(\times 10^{\circ} / l\right)\end{array}$} & \multicolumn{2}{|c|}{ Up to 1 November 1988} & \multicolumn{2}{|c|}{ After 1 November 1988} & \multirow[b]{2}{*}{ Relative risk } & \multirow{2}{*}{$\begin{array}{c}95 \% \\
\text { Confidence } \\
\text { interval }\end{array}$} & \multirow[b]{2}{*}{ p Valu } \\
\hline & $\begin{array}{l}\text { Patient years } \\
\text { free of AIDS }\end{array}$ & $\begin{array}{l}\text { No of AIDS } \\
\text { cases }\end{array}$ & $\begin{array}{l}\text { Patient years } \\
\text { free of AIDS }\end{array}$ & $\begin{array}{l}\text { No of AIDS } \\
\text { cases }\end{array}$ & & & \\
\hline$\leqslant 0.05$ & $3 \cdot 6$ & 8 & $12 \cdot 6$ & 7 & $4 \cdot 0$ & 1.45 to 11.03 & $<0.01$ \\
\hline$\leqslant 0 \cdot 10$ & $10 \cdot 2$ & 11 & $18 \cdot 9$ & 7 & 2.91 & 1.13 to 7.51 & 0.03 \\
\hline$\leqslant 0 \cdot 15$ & $28 \cdot 3$ & 16 & $30 \cdot 5$ & 7 & $2 \cdot 46$ & 1.01 to 5.98 & $<0.05$ \\
\hline$\leqslant 0 \cdot 20$ & $58 \cdot 2$ & 19 & $47 \cdot 6$ & 8 & 1.94 & 0.85 to 4.43 & 0.1 \\
\hline
\end{tabular}

cystis pneumonia (17 patients), oesophageal candidiasis (three), non-Hodgkin's lymphoma (three), AIDS wasting syndrome (three), cerebral toxoplasmosis (two), septicaemia (two), aspergillosis (one), chickenpox pneumonia (one), and HIV encephalopathy (one). Of these patients, 19 had one AIDS defining condition and 14 more than one. One patient, who survived four years from the initial diagnosis of AIDS with pneumocystis pneumonia, had six AIDS defining events: pneumocystis pneumonia, cryptococcal meningitis, salmonella septicaemia, cryptosporidiosis, pneumocystis pneumonia, and HIV related encephalopathy.

The Kaplan-Meier estimate for the rate of progression to AIDS at 11 years was $31 \%(12 \%$ to $50 \%)$ in patients aged less than 25 years at seroconversion. In those aged 25 or more it was $56 \%$ (39\% to $73 \%$; $\mathrm{p}<0 \cdot 0001$ ).

In patients with previous cytomegalovirus infection, shown by the presence of IgG antibodies to the virus, the estimated rate of progression to AIDS at 11 years was $59 \%(39 \%$ to $81 \%)$ compared with $21 \%(6 \%$ to $36 \%)$ in patients without cytomegalovirus IgG. The relative risk was $3.0(1.4$ to $6 \cdot 8 ; p=0.006)$. However, patients infected with cytomegalovirus tended to be older than those not infected, and after adjustment for age the significance fell $(p=0.03)$.

Twenty seven patients showed p24 antigenaemia; seven were positive for p24 antigen at the time of their first positive HIV antibody test result, but in the remaining patients the time to devleop p24 antigen after seroconversion was variable.' ${ }^{1}$ Sixteen $(59 \%)$ patients with the antigen subsequently developed AIDS compared with 17 of $84(20 \%)$ patients who were negative for $\mathrm{p} 24$ antigen $(\mathrm{p}<0.001)$.

\section{EFFECT OF TREATMENT}

Treatment for patients without AIDS began in November 1988. To assess whether the risk of AIDS changed we considered the total patient years free of AIDS after the CD4+ count had fallen below certain cut off levels and the number of cases of AIDS that have occurred (table). Whichever cut off was chosen there was a higher risk of progression to AIDS before 30 November 1988.

In a further analysis of the 29 patients with AIDS in whom the CD4+ count was known at the time that AIDS developed those developing AIDS before 30 November 1988 had significantly higher CD4+ counts than those developing AIDS after 30 November 1988, geometric means 0.11 and 0.034 respectively $(p=0 \cdot 003)$. This difference remained virtually unchanged after adjustment for age and cytomegalovirus infection as well as after exclusion of patients who developed AIDS with a CD4+ count above $0 \cdot 2 \times 10^{9} / 1$.

We also investigated the effect of treatment by an alternative method. We have reported a method for predicting future numbers of AIDS cases based on a linear fall in CD4+ lymphocyte counts. ${ }^{10}$ This was achieved by fitting a straight line through the plot of patients' CD4+ counts over time by linear regression and noting the intersection of that line with the CD4+ count $0.05 \times 10^{9} / 1$. This was the median value at which AIDS occurred and was thus chosen as the point at which AIDS would be expected to occur in patients without AIDS. Such a simple model has limited application for prediction in an individual but was found to be useful for groups of patients. Using data up to November 1988 in our cohort, we were able to predict the number of patients who would progress to AIDS by each calendar year. Such a prediction could be made for only the 81 patients for whom five or more CD4+ counts were then available.

We compared subsequently observed numbers of cases of AIDS with those expected on the basis of the 


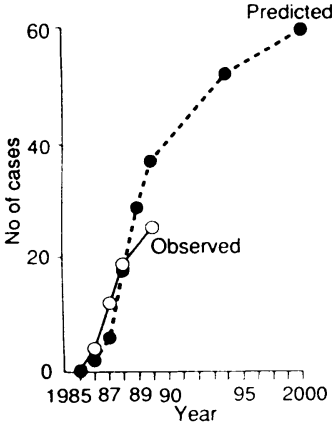

FIG 2-Observed and predicted cumulative numbers of patients progressing to AIDS by calenda year in the 81 patients for whom five or more CD4+ lymphocyte counts were available in November 1988 model. Three cases of AIDS developed in 1989, two in 1990 up until November 1990, and a further case in December 1990. The observed numbers of patients progressing to AIDS in our cohort by calendar year begin to diverge from the curve of predicted numbers of patients at the end of 1988, the time at which treatment for patients without AIDS was first introduced (fig 2). The differences between observed and predicted numbers for 1990 were significant $(p=0.03)$.

Of 26 patients on primary prophylaxis with pentamidine for a total of 363 months (median 14 (range 2-22) months), only one has developed pneumocystis pneumonia. This patient admitted non-compliance.

Of the nine patients with thrombocytopenia (platelet count $<50 \times 10^{9} / 1$ ), seven (treated with zidovudine, intravenous interferon, and immunoglobulin before splenectomy) have remained in remission for a median of 30 (range 2-47) months, and two (treated with intravenous interferon and immunoglobulin and splenectomy followed by intravenous interferon respectively) have died without achieving remission.

\section{Discussion}

The estimated rate of progression to AIDS 11 years after seroconversion in our cohort was $42 \%$, and we found some evidence that treatment is slowing progression of HIV disease. Furthermore, it is clear from serial measurements of the rate of fall of CD4+ lymphocyte count that there is considerable individual variability in progression rates, ${ }^{11}$ and this is shown by our earliest patient to seroconvert, ${ }^{3}$ who remained asymptomatic 10 years after seroconversion. He was negative for cytomegalovirus IgG and p24 antigen. In the large San Francisco cohort of homosexual men $19 \%$ of those who seroconverted during 1977-80 remained asymptomatic in $1990 .^{2}$

Our progression rate is similar to that in homosexual men $^{2}$ and other haemophilic cohorts, ${ }^{12}{ }^{13}$ while transfusion recipients, ${ }^{14}$ drug misusers, ${ }^{16}$ and African women (Anzala $e t$ al, sixth world AIDS congress, San Francisco, 1990) have been reported to progress somewhat faster. Kaposi sarcoma is rare among haemophilic patients ${ }^{113}$ and since this tends to occur at higher CD4+ lymphocyte counts than other AIDS defining conditions $^{17}$ it might be expected that people with haemophilia would progress more slowly than homosexual men. On the other hand, haemophilic cohorts usually include a higher proportion of older patients and their faster progression may balance the trend. While the faster rate of progression in drug misusers may be related to persistent injection of drugs, ${ }^{16}$ in recipients of blood transfusion a larger infecting inoculum or more aggressive strains of HIV is thought to contribute. ${ }^{15}$ The documented high rate of progression among African women will need to be compared with that in other female cohorts to see if there are sexual differences.

Age still remains a powerful factor influencing progression, as has also been shown in a cohort of 319 haemophilic patients with documented seroconversion in the United States ${ }^{13}$ and in patients in Britain..$^{18}$ Older patients are at higher risk of progression than their younger counterparts even if their CD4+ lymphocyte counts are the same. ${ }^{19}$ This may also be a factor in the faster rate of progression in recipients of blood transfusions: the median age of transfusion recipients in an earlier study was 46 years (range 1 day87 years) $)^{15}$ and in our study was 24 years (range 2-77 years). Thus the flattening of progression in our cohort might be partly due to older people having progressed earlier on. We projected that by 15 years from seroconversion without treatment $25 \%$ will still not have developed AIDS ${ }^{10}$; some younger patients clearly have the prospect of a slow, indolent disease.
The divergence of the observed numbers of AIDS cases from those expected (fig 2) could be interpreted as due to a poor fitting model. However, this model fitted closely up until November $1988,,^{10}$ and the consistency of the results with other analyses presented suggest that this is not the case.

The role of cytomegalovirus as a cofactor is still controversial. The results described here extend our earlier report that patients positive for antibodies to cytomegalovirus progress to AIDS more quickly and that this effect is independent of age. ${ }^{20}$ Although others have reported the effect of cytomegalovirus in patients infected with HIV, ${ }^{1-23}$ these studies are technically flawed. ${ }^{2+}$ No other study has reported data to relate cytomegalovirus serostatus to progression after HIV seroconversion, and further studies are required in defined patient groups to clarify this issue.

Detection of p24 antigen before symptomatic disease has also been shown to correlate with prognosis. ${ }^{25}$ Our patients showed a varied pattern of p24 antigenaemia, ${ }^{1}$ and we found that it was associated with poor prognosis. Others have also shown that haemophilic patients with a low p24 antibody titre and high gp120 antibody titre at time of HIV seroconversion are more likely to develop p24 antigenaemia; again these patients develop HIV related disease more rapidly. ${ }^{20}$ The persistence of p24 antigen seems to mark a group of patients with poor immune response to HIV, resulting in a faster fall in CD4 + lymphocyte count and faster progression to AIDS."

Our finding - that the rate of progression to AIDS has slowed since 1988-has also been shown in the United States since mid-1987. ${ }^{27}$ This is almost certainly partly related to the introduction of antiviral treatment and prophylaxis against pneumocystis pneumonia. Zidovudine has already been shown to be beneficial for haemophilic patients with symptoms of HIV infection, and although the haematological toxicity is high it is mostly asymptomatic, reversible, and well tolerated. ${ }^{28}$ We now treat asymptomatic patients with a CD4+ lymphocyte count of $0.2 \times 10^{9} / 1$, at which level there begins to be a significant probability of developing AIDS.' The treatment of early HIV infection remains controversial. ${ }^{29} 30$ The results of the Concorde trial may also answer the questions of efficacy and toxicity of zidovudine in the long term.

There is no doubt about the efficacy of prophylaxis against pneumocystis pneumonia, but the best method has not been established..$^{31}$ In our patients who are used to home treatment with clotting factor concentrate, most chose to self administer pentamidine at home.

Finally haemophilic patients with HIV associated thrombocytopenia present special management issues in view of the pre-existing coagulopathy. ${ }^{32}{ }^{33}$ Thrombocytopenia may be the first manifestation of HIV infection and occurs in $5-10 \%$ of asymptomatic patients compared with $25-45 \%$ of people with AIDS. ${ }^{3}$ Zidovudine is the least invasive and therefore first choice of treatment. ${ }^{4}$ Splenectomy with preoperative intravenous immunoglobulin has also been shown to be effective in haemophilic patients. "2 Although we have shown a substantial and longlasting response to interferon in one patient ${ }^{35}$ and this can be self administered intravenously, there are only anecdotal reports of similar use. ${ }^{3637}$ This therefore remains our treatment of last resort.

It is now clear that HIV disease has a long and variable latent period principally determined by the rate of fall in the CD4+ count. "Our results suggest that treatment may be beginning to slow the progression of HIV disease in this haemophilic cohort. The similar progression rates to those in homosexual men suggest that our findings may be applicable to patients without haemophilia who are infected with HIV. 
We thank Mrs Julia Young for preparing the manuscript and the department of medical illustration, Royal Free Hospital and School of Medicine for drawing the figures.

1 Lee CA, Phillips AN, Elford J, Miller EJ, Bofill M, Griffiths PD, et al. The natural history of human immunodeficiency virus infection in a haemophilic natural history of human immunodeficind
cohort. Br f Haematol 1989;73:228-34.

2 Rutherford GW, Lifson AR, Hessol NA, Darrow WW, O'Malley PM, Buchbinder SP, et al. Course of HIV-I infection in a cohort of homosexual and bisexual men: an 11 year follow-up study. B.MF 1990;301:1183-9.

Lee CA, Webster A, Griffiths PD, Kernoff PBA. Symptomless HIV infection after more than ten years. Lancet 1990;335:425-6.

4 Fischl MA, Richman DD, Grieco MH, Gottlieb MS, Volberding PA, Laskin $\mathrm{OL}$, et al. The efficacy of azidothymidine (AZT) in the treatment of patients with AIDS and AIDS-related complex: a double-lind, placebo-controlled trial. $N$ Engl F Med 1987;317:185-91.

5 Simonds AK, Newman SP, Johnson MA, Talace N, Lee CA, Clarke SW. Simple nebuliser modification to enhance alveolar deposition of pentamidine. Lancet 1989;ii:953.

6 Simonds AK, Newman SP, Johnson MA, Talace N, Lee CA, Clarke SW Alveolar targeting of aerosol pentamidine. Am Rev Respir Dis 1990;141: $827-9$.

7 Guidelines for prophylaxis against pneumocystis carinii pneumonia for persons infected with human immunodeficiency virus. MMWR 1989;38: $1-9$.

8 Kaplan EL, Meier P. Non-parametric estimation from incomplete observations. Fournal of the American Statistical Association 1958;53:457-81.

9 Breslow NE, Dav NE. Statistical methods in cancer research. Vol II. The design and analysis of cohort studies. Lyon: International Agency for Research on Cancer, 1987:1-406. (Scientific Publication 82.

10 Phillips A, Lee CA. Elford J, Janossy G, Bofill M, Timms A, et al. Prediction of progression to AIDS by analysis of CD4 lymphocyte counts in a haemophilic cohort. AIIDS 1989:3:737-41.

11 Phillips AN, Lee CA, Elford J, Janossy G, Timms A, Bofill M, et al. Serial CD4 lymphocyte counts and development of AIDS. Lancet 1991;337: $389-92$

12 Eyster ME, Gail MH, Ballard JO, Al-Mondhiry H, Goedert JJ. Natural history of human immunodeficiency virus infections in haemophiliacs: effects of T-cell subsets, platelet counts and age. Ann Intern Med 1987;107: $1-6$

13 Goedert JJ, Kessler CM, Aledort LM, Biggar RJ, Andes WA, White GC, et al. A prospective study of human immunodeficiency cirus type I infection and the development of AIDS in subjects with haemophilia. $N$ Engl I Med 1989;321:1141-8.

14 Giesecke J. Scalia-Tomba (i, Berglund O, Berntorp E, Schulman S, Stigendal L. Incidence of symptoms and AIDS in 146 Swedish haemophiliacs and blood transfusion recipients infected with human immunodeficiency virus. BM7 1988:297:99-102.

15 Ward JW, Bush TJ, Perkins HA, Lieb LE, Allen JR, Goldfinger D, et al. The natural history of transfusion-associated infection with human immunodeficiency virus. $N$ Engl 7 Med 1989-321:947-52.

16 Weber R, Ledergerber B, Opravil M, Siegenthaler W, Luthy R. Progression of HIV infection in misusers of injected drugs who stop injecting or follow a programme of maintenance treatment with methadone. $B M 7$ 1990;301:2-5.

17 Lane HC, Masur H, Gelmann EP, Longo DL, Steis RG, Chused T, et al. Correlation between immunologic function and clinical subpopulations of patients with the acquired immune deficiency syndrome. Am f Med 1985;78:417-22.

18 Darby SC, Rizza CR, Doll R, Spooner RJD, Stratton JM, Thakrar B. Incidence of AIDS and excess of mortality associated with HIV in haemophiliacs in the UK. Report on behalf of the directors of haemophilia centres in the UK BMF 1989;298:1064-8.

19 Phillips AN, Lee CA, Elford J, Webster A, Janossy G, Timms A, et al. More rapid progression to AIDS in older HIV infected people: the role of CD4 $T$ cell counts. I Acquir Immune Defic Syndr (in press).

20 Webster A, Lee CA, Cook DG, Grundy JE, Emery VC, Kernoff PBA, et al. Cytomegalovirus infection and progression towards AIDS in haemophiliacs with human immunodeficiency virus infection. Lancet 1989;ii:63-6.

21 Jackson JB, Erice A, Englund JA, Edson JR, Balfour HH Jr. Prevalence of cytomegalovirus antibody in hemophiliacs and homosexuals infected with human immunodeficiency virus type I. Transfusion 1987;28:187-9.

22 Barnas S, O"Toole C, Colvin B. Cytomegalovirus infection and progression to AIDS. Lancel 1989;ii:336.

23 Rugman FP, Mannion PT, Hay CRM, Bolton-Maggs P, Roberts D, Mutton KJ. Cytomegalovirus, serum $\beta_{2}$ microglobulin, and progression to AIDS in HIV-seropositive haemophiliacs. Lancet 1989;ii:631.

24 Webster A, Grundy JE, Lee CA, Emery VC, Cook DG, Kernoff PBA, et al. Cytomegalovirus infection and progression to AIDS. Lancet 1989-ii:681.

25 de Wolf F, Goudsmit J, Paul DA, Lange JM, Hooijkas $C$ Schellekens $P$, et al. Risk of AIDS related complex and AIDS in homosexual men with persistent HIV antigenaemia. $B M \mathcal{F}$ 1987;295:569-71.

26 Cheingsong-Popov R, Panagiotidi C, Bowcock S, Aronstam A, Wadsworth J, Weber J. Relation between humoral responses in HIV gag and env proteins at seroconversion and clinical outcome of HIV infection. $B M \mathcal{F}$ 1991;302 at seroc.

27 HIV prevalence estimates and AIDS case projections for the United States.

28 Lim SG, Lee CA, Kernoff PBA. Zidovudine treatment for anti-HIV positive haemophiliacs. Clin Lab Haematol 1990;12:367-78.

29 Swart AM. Weller I, Darbyshire JH. Early HIV infection: to treat or not to treat? BMF 1990;301:825-6.

30 Friedland GH. Early treatment for HIV. N Engl F Med 1990;322:1000-2.

31 Medina I, Mills J, Leoung G, Hopewell DC, Lee B, Modin G, et al. Oral therapy for Pneumocystis carinii pneumonia in the acquired immunodeficiency syndrome. A controlled trial of trimethoprim-sulfamethoxazole versus trimethoprim-dapsone. $N$ Engl $\mathcal{F}$ Med 1990;323:776-82.

32 Beard J, Savidge GF. High-dose intravenous immunoglobulin and splenectomy for the treatment of HIV-related immune thrombocytopenia in patients with severe haemophilia. Br $\mathcal{H}$ Haematol 1988;68:303-6.

33 Lim SG, Lee CA, Kernoff PBA. The treatment of HIV-associated thrombocytopenia in haemophiliacs. Clin Lab Haematol 1990;12:237-45.

34 Pottage JC, Benson CA, Spear JB, Landay AL, Kessler HA. Treatment of human immunodeficiency virus-related thrombocytopenia with zidovudine. GAMA 1988:260:3045-8.

35 Lee CA, Kernoff PBA, Karayiannis P, Thomas HC. Interferon therapy for chronic non-A non-B and chronic delta liver disease in haemophilia.

36 Lever AML, Brook MG, Yap I, Thomas HC. Treatment of thrombocytopeni with alfa interferon. BMF 1987;295:1519-20.

7 Proctor SJ, Jackson G, Carey P, Stark A. Short-course alpha-interferon therapy in severe unresponsive immune thrombocytopenic purpura. Lance $1988 ; \mathrm{i}: 947$
Departments of Chemical Pathology and Medicine, Chinese University of Hong Kong, Prince of Wales Hospital, Shatin, NT, Hong Kong

A Chan, MRCPATH, lecturer

$\mathrm{R}$ Shinde, PHD, research fellow

C C Chow, MRCP, senior medical officer

C S Cockram, FRCP, senior lecturer

R Swaminathan, FRCP, professor

\section{Correspondence to:}

Professor R Swaminathan

Department of Clinical

Biochemistry, United

Medical and Dental Schools,

Guy's Hospital, London

SE1 9RT.

BMF 1991;303:1096-9

\title{
In vivo and in vitro sodium pump activity in subjects with thyrotoxic periodic paralysis
}

\author{
A Chan, R Shinde, C C Chow, C S Cockram, R Swaminathan
}

\section{Abstract}

Objective-To examine whether sodium pump activity plays a part in the pathogenesis of thyrotoxic periodic paralysis.

Design-Measurement of platelet sodium-potassium ATPase and in vivo sodium pump activities in healthy subjects and thyrotoxic subjects with and without paralysis.

Setting-University hospital in Hong Kong.

Subjects-21 healthy subjects, 23 untreated thyrotoxic subjects, 13 untreated men with periodic paralysis, seven treated thyrotoxic subjects, and six treated men with periodic paralysis.

Main outcome measures-Platelet $\mathrm{Na}^{+}, \mathrm{K}^{+}$. ATPase activity and plasma rubidium concentration after oral loading.

Results-Median (range) platelet $\mathrm{Na}^{+}, \mathrm{K}^{+}$. ATPase activity in thyrotoxic subjects was 253 (169821) $\mu \mathrm{mol}$ inorganic phosphate/h/g proteinsignificantly higher than that in healthy subjects $(134$ (81-180) $\mu \mathrm{mol} / \mathrm{h} / \mathrm{g}$ protein; $\mathbf{p}<0.001) . \mathrm{Na}^{+}, \mathrm{K}^{+}$. ATPase activity in those with periodic paralysis was $374(195-1196) \mu \mathrm{mol} / \mathrm{h} / \mathrm{g}$ protein, again significantly higher than that in healthy subjects $(p<0.001)$ and that in other thyrotoxic subjects $(p<0.01)$ despite similar degrees of hyperthyroidism. Activities in treated thyrotoxic subjects with and without periodic paralysis were $148(110-234)$ and $131(86-173) \mu \mathrm{mol}$ $\mathrm{h} / \mathrm{g}$ protein respectively. Mean $(95 \%$ confidence interval) plasma rubidium concentration five hours after oral administration in thyrotoxic subjects $\mathbf{7 . 0}$ (6.6 to 7.5$) \mu \mathrm{mol} / \mathrm{l})$ was significantly lower than in healthy subjects $(10.2(9.5$ to 10.9$) \mu \mathrm{mol} / \mathrm{l} ; \mathbf{p}<0.001)$ and higher than in those with periodic paralysis $(6 \cdot 0$ $(5.7$ to 6.3$) \mu \mathrm{mol} / 1 ; \mathrm{p}<0.01)$.

Conclusions-Sodium pump activity in untreated subjects with periodic paralysis is higher than in other thyrotoxic subjects, and this may be responsible for the hypokalaemia.

\section{Introduction}

Hypokalaemic periodic paralysis, in association with thyrotoxicosis, occurs almost exclusively in oriental men $^{1-4}$ and has been reported to occur in $13-26 \%$ of thyrotoxic Chinese men. ${ }^{24}$ It is about 70 times more 